addition to smoking. The occupational variation in risk of bladder cancer is small when adjusted for smoking.

\section{EARLY MARKERS OF CARDIOVASCULAR DISEASE ARE ASSOCIATED WITH OCCUPATIONAL EXPOSURE TO POLYCYCLIC AROMATIC HYDROCARBONS}

${ }^{1}$ Ayman Alhamdow* ${ }^{*}{ }^{2}$ Christian Lindh, ${ }^{1,2}$ Maria Albin, ${ }^{1}$ Per Gustavsson, ${ }^{2}$ Håkan Tinnerberg,
${ }^{1,2}$ Karin Broberg. ${ }^{1}$ Karolinska Institutet, Stockholm, Sweden; ${ }^{2}$ Lund University, Lund, Sweden

10.1136/oemed-2018-ICOHabstracts. 1057

Introduction Occupational exposure to polycyclic aromatic hydrocarbons (PAH) from soot is common and has been associated with increased risk of cardiovascular disease (CVD); the association, however, has only been indicated, not established. Our aim was to investigate occupational exposure to PAH and early markers of CVD.

Methods A cross-sectional study of 151 chimney sweeps and 152 controls, all males, from Sweden was conducted between 2011-2015. Participants answered a questionnaire and gave blood and urine samples. Urinary PAH metabolites were measured using LC-MS/MS: 1-hydroxypyrene (1-OH-PYR), 2hydroxyphenanthrene (2-OH-PH), 3-hydroxybenzo[a]pyrene (3-OH-BaP), and 3-hydroxybenzo[a]anthracene (3-OH-BaA). Blood pressure (BP) and serum biomarkers were measured (Creactive protein, homocysteine, gamma-glutamyltransferase, cholesterol, HDL, LDL, and triglycerides), to estimate the risk of CVD.

Results Chimney sweeps had up to 7-fold higher concentrations of PAH metabolites in urine than controls $(p<0.001)$ : median concentrations (adjusted for specific gravity) for 1$\mathrm{OH}-\mathrm{PYR}, 2-\mathrm{OH}-\mathrm{PH}, 3-\mathrm{OH}-\mathrm{BaP}$, and $3-\mathrm{OH}-\mathrm{BaA}$ were $0.56 \mu \mathrm{g} /$ $\mathrm{L}, \quad 0.78 \mu \mathrm{g} / \mathrm{L}, \quad 4.75 \mathrm{ng} / \mathrm{L}$, and $6.28 \mathrm{ng} / \mathrm{L}$, respectively. $\mathrm{PAH}$ metabolites correlated positively with the amount of soot sweeping as a percentage of total work $(p<0.001)$. Chimney sweeps had increased homocysteine, cholesterol, and HDL $(\beta=3.4 \mu \mathrm{mol} / \mathrm{L}, 0.43 \mathrm{mmol} / \mathrm{L}$, and $0.13 \mathrm{mmol} / \mathrm{L}$, respectively, $\mathrm{p} \leq 0.003$, adjusted for age, BMI, and smoking). 2-OH-PH, 3$\mathrm{OH}-\mathrm{BaP}$, and 3-OH-BaA were positively associated with diastolic BP in chimney sweeps $(\mathrm{p}<0.044$, adjusted for age, BMI, and smoking).

Conclusions Working with soot resulted in clear exposure to $\mathrm{PAH}$, and in turn, an elevated risk for CVD. These findings indicate the need to raise awareness of protective measures that can decrease PAH exposure during work and in the general environment.

\section{OCCUPATIONAL ACCIDENTS REPORTED WITHIN THE FORENSIC MEDICINE DEPARTMENT}

D Lahlou*, I El Amri, B Benali, A Chbani, A Elkholti. Casablanca Faculty of medicine and pharmacy, Hassan II university, Morocco

\subsection{6/oemed-2018-ICOHabstracts. 1058}

Introduction Professions in health care settings are characterised as having a high professional risk, in addition tohealth care workers, all occupations are carried out with specific constraints, exposing personnel to several risks, due to accidents involving exposure to biological products, physical nuisance, chemical toxicity and stress.
Materials and methods Our work consists of a retrospective study of 119 cases of occupational accidents declared by staff (3684 employees) of the Ibn Rochd University Hospital in Casablanca, over a period of 3 years (between January 2010 and December 2012).

Results Ninety women and twenty ninemen were enumerated, with a sex ratio of 0.32 .The average age was 45.58 years, with extremes of 23 to 60 years.

Nurses and nursing assistants represent $42,01 \%$ of the cases, followed by service agents (31\%), then doctors $(15,12 \%)$. Administrative personnel remainsas the least the exposed category $(6,72 \%)$.

The most frequent accidents are related to falls $(52,08 \%)$, followed by blood exposure (18,48\%), while musculoskeletal disorders come far after with a percentage of $3.36 \%$. The temporary work disability, stands between 3 days and 3 months, with a prolongation that can go up to 12 months. Thenumber of patient who had a permanentpartial disability was 28 , with rates varying from $2 \%$ to $18 \%$. None of them needed a job change orreclassification.

Conclusion Hospital staff is exposed to a number of risks, this requires taking somenecessarymeasures to ensure the safety and protect the health of healthcare workers, taking as a base general principles of prevention.

\section{SELF-DETERMINING MEDICAL LEADERSHIP NEEDS OF OCCUPATIONAL MEDICINE PHYSICIANS - A STUDY THAT CAN RESHAPE THE MEDICAL LEADERSHIP TRAINING}

1,2,3Prosenjit Giri* ${ }^{3}{ }^{3}$ Jill Aylott, ${ }^{4}$ Karen Kilner. ${ }^{1}$ Sheffield Teaching Hospitals Nhs Trust, Worksop, UK; ${ }^{2}$ Sheffield University, UK; ${ }^{3}$ International Academy of Medical Leadership, Dronfield, Derbyshire, UK; ${ }^{4}$ Centre for Leadership in Health and Social Care, Sheffield Hallam University, Sheffield, UK

\subsection{6/oemed-2018-ICOHabstracts. 1059}

Introduction Physician leadership, irrespective of hierarchy, is an integral part of delivering complex modern-day healthcare which thrives on quality improvement and efficiency savings. Doctors' participation in Medical Leadership however remains fragmented and patchy as has been their leadership training. Absence of empirical research in designing strategies to engage and motivate doctors and validated leadership qualities assessment instruments may have compounded the problem further. Methods This national study, facilitated by the Faculty of Occupational Medicine of the UK (FOM), explored factors that motivate the UK-based Occupational Medicine Physicians (OHPs) to engage in leadership roles alongside assessment of their leadership competency and training needs by framing an inquiry within Self-Determination Theory using the 7 domain National Health Service Leadership Academy self-assessment tools on a web-based platform. The data were analysed using descriptive statistics and simple inferential methods.

Results 25\% (250/1000) of the UK-based FOM $(n=1000)$ members participated. OHPs were open about reporting their leadership strengths (mean score; $4.26 / 8$ across 7 domains; highest in personal qualities; 5.77/8 and lowest in Creating the Vision; 2.73/8). Irrespective of personal level of competency, they universally recognised the need for life-long leadership training. Experience of management role (6 domains; $\mathrm{p}<0.05)$ was identified as the single most influencing factor behind a doctor's confidence. In multivariate regression, management experience accounted for the usefulness of leadership 
training, suggesting that doctors learn best through applied 'leadership learning' as opposed to theory-driven programmes. Conclusions Drawing on Self-Determination Theory this study provides a theoretical framework for engaging doctors in Medical Leadership; assessing their leadership competency and learning needs and setting up reliable leadership training programmes. Doctors' ability to reliably determine their learning needs and the invaluable role of hands-on leadership/management experience in boosting doctors' leadership confidence, calls for more personalised and relevant learning plan that can build on their previous experience and expertise.

\section{WARNING BELL AGAINST THE RISE OF VIOLENCE WITH REGARD TO HEALTH PROFESSIONALS IN THE EMERGENCY DEPARTMENT}

M Lghabi*, W Allouche, B Benali, R Rhattas, A El Kholti. Casablanca Faculty of Medicine and Pharmacy, Hassan II University, Morocco

\subsection{6/oemed-2018-ICOHabstracts. 1060}

Introduction The violence is strongly present in the current hospital context, where the violence in the hospital is increasing, in particular with regard to harm to persons. The emergency department, as the hospital's multidisciplinary gateway, is now the most widespread hospital service with the highest number of acts of violence.

Methods This is a cross-sectional study conducted with the emergency department staff at a prefectural hospital in Casablanca using a self-administered questionnaire. The aim is to evaluate the violence in the emergency department and to define the methods of prevention.

Result Only 30 people (37.5\%) participated in the survey, with a female predominance $(66.6 \%)$. The average age was 35 years. $90 \%$ of our respondents feel exposed to violence in the performance of their duties. Nurses are the most exposed occupational category (34.6\%). Visitors and accompanying persons were the main perpetrators of the violence $(66.6 \%)$. Violence occurs more at night (39\%). 69\% of violence is harmful to people. Only $33.3 \%$ of the violence was reported to the administration.

Discussion Several studies, including ours, show a female predominance, this could be explained by the feminization of health personnel. In our study, visitors or accompanying persons were the most responsible for the violence $(66.6 \%)$, which is in line with several Moroccan studies. However, the 2014 annual report of the national observatory of violence in the health sector shows that in $72 \%$ of the perpetrators of the violence were patients. Personal injury is the most frequent, which is in accordance with the literature. On the other hand, the reporting rate remains relatively low compared to the literature.

Conclusion Violence against health personnel has become a daily reality. Its continuous rise has sounded the alarm calling to control this risk. Efforts should be pursued towards evaluation and prevention in order to optimise exercise safety.

\section{APPLYING PRACTICE GUIDELINES IN OCCUPATIONAL MEDICINE}

Tee Guidotti. Occupational + Environmental Health and Safety, Washington, DC, USA

10.1136/oemed-2018-ICOHabstracts.1061
Systematic critical appraisal and clinical epidemiology as represented by the Cochrane Collaboration have provided the methodology for the formulation of clinical 'practice guidelines' in many specialties and in primary care. Practice guidelines are valuable in establishing the standard of care, controlling costs, and improving consistency of outcomes. Critics charge that practice guidelines suppress innovation, constrain the practice of medicine, ignores differences in patient population, and are overly rigid given individual patient characteristics. The application of clinical guidelines to occupational medicine in the United States was pioneered by the American College of Occupational and Environmental Medicine (ACOEM), which developed and maintains the ACOEM Practice Guidelines (APG) using a Cochrane-like system of expert panels reviewing peer-reviewed evidence. The APG has become a widely accepted authoritative reference used especially workers' compensation systems to establish the standard of care. Problems include: Uneven evidentiary base (abundant and uninformative in the case of back pain, scanty and largely irrelevant for elbow and other issues); absence of clinical trials for occupationally-relevant outcomes; obstacles to performing outcomes studies and workplace intervention trials for injuries; characteristics of occupational disease such as latency, infrequency, and certainty of diagnosis; opposition by practitioners, mostly outside of occupational medicine; rigidity in application, not taking into account co-morbidity, patient characteristics, and complications; over-reliance on meta-analysis (which could be corrected by Bayesian analysis). Effectiveness of practice guidelines in occupational medicine has not been systematically studied except for cost, however. Performance assessment has been anecdotal. After having overseen the early APG program, the author's view was that practice guidelines for were a beneficial but partial solution, addressing different issues than in general medicine. The opinions expressed here are those of the authors and do not reflect a position of ACOEM.

\section{AVIATION MEDICINE: THE GLOBAL CHALLENGES TO REGULATORS AND AIRLINES}

Marcus GP Wong*. Durham University, Durham, UK

\subsection{6/oemed-2018-ICOHabstracts. 1062}

Aim of special session An overview about contemporary global challenges to aviation regulators and airlines

${ }^{1}$ Dr Tom Gaffney, ${ }^{2}$ Dr Elizabeth Wilkinson

${ }^{1}$ Irish Aviation Authority, Dublin, Republic of Ireland

${ }^{2}$ British Airways Health Services, Harmondsworth, UK

Regulatory aviation medicine/aeromedicine, a subsection of occupational medicine, aims to determine whether pilots are medically fit to fly either routinely or in response to a decrease in medical fitness. Traditionally, change occurs very slowly in aviation medicine, new treatments and technologies must be evidence based and well established before the standards will change. The role of the aviation medical regulator ('medical assessor') has become more demanding in the past 20 years as many complex ongoing clinical conditions have now been deemed compatible with safe flight. Therefore, many pilots are now deemed fit to fly where formerly their careers would have ended. In addition, regulators (competent authorities) around the world determine the medical standard 